Rapid Reviews COVID-19

\title{
Review 1: "Deaths of Despair and the Incidence of Excess Mortality in 2020"
}

Published on: Feb 22, 2021

License: Creative Commons Attribution 4.0 International License (CC-BY 4.0). 


\section{$\underline{\text { RR:C19 Evidence Scale rating by reviewer: }}$}

- Misleading. Serious flaws and errors in the methods and data render the study conclusions misinformative. The results and conclusions of the ideal study are at least as likely to conclude the opposite of its results and conclusions than agree. Decision-makers should not consider this evidence in any decision.

\section{Review:}

This paper argues that

"Deaths of despair (drug overdose, suicide, alcohol) in 2017 and 2018 are good predictors of the demographic groups with [non-COVID excess deaths] NCEDs in 2020. The NCEDs are disproportionately experienced by men aged 15-55, including men aged 15-25. Local data on opioid overdoses further support the hypothesis that the pandemic and recession were associated with a 10 to 60 percent increase in deaths of despair above already high pre-pandemic levels." [Mulligan, Abstract]

The author misrepresents the increase in drug overdose deaths that were predictable for 2020 , because he uses only data from 2015-2018 to forecast what could have been expected for 2020 . This is puzzling, given that the data for 2019 are publicly available.

Unfortunately, drug overdose mortality began rising early in 2019, after having taken something of a holiday in 2018. https://www.cdc.gov/nchs/nvss/vsrr/drug-overdose-data.htm This is thought to be largely due to fentanyl breaking through west of the Mississippi in 2019. https://pubmed.ncbi.nlm.nih.gov/33038637/

Drug overdose mortality was accelerating prior to the arrival of COVID-19, and the shape of that acceleration would have taken in spring and summer of 2020 without the COVID pandemic is not known. It is an error to attribute all of this to COVID. The results presented are misleading.

The author's own graph of two counties he examines (Cook County, IL and San Diego County, CA) show that drug overdose mortality had been rising in both counties since early 2019 (see Figure 5).

While it is possible that stay at home orders, or simply people feeling that they should stay at home, added to the rise in drug overdose mortality, it is not possible, using the data the author uses, to parse out what part of the increase is due to the rise in fentanyl, and what part is due to the COVID-19 epidemic. 